\title{
The Impact of Aqua Jogging Exercise on Hematological Response in Obese Women
}

\author{
Siti Baitul Mukarromah \\ Sport Science Department \\ Universitas Negeri Semarang \\ Semarang, Indonesia \\ sitibaitul@mail.unnes.ac.id
}

\author{
Hardhono Susanto \\ Medicine Faculty \\ Diponegoro University \\ Semarang, Indonesia \\ haserra2000@yahoo.com
}

\begin{abstract}
This study aims to determine the effect of aqua jogging on the hematology in obese women. Experimental Randomized pre-test post-test control group design, 36 obese women, age 45-50 years, divided into 3 groups, aqua jogging, resistance training and control $(n=12)$. Body Mass Index $(B M I)$ hematological blood measured before and after treatment. Hypothesis test using One Way Anova test. The hematologic change of the aqua jogging group was higher than resistance training and control $(\mathbf{p}<0.05)$. In contrast, the increase in erythrocytes in the resistance training group was higher than aqua jogging and control $(p<0.05)$. Aqua jogging affects the hematological levels in obese women.
\end{abstract}

Keywords-body mass index, hemoglobin, hematocrit, erythrocyte

\section{INTRODUCTION}

Obesity is a worldwide health problem. In Indonesia, Riskesdas records that there are more than 40 million obese or overweight adults[1]. Obesity conditions occur when the intake of the number of calories consumed exceeds the number of calories expended in a long time[2,3]. Although genetic factors influence obesity, but diet and physical activity determine an individual eventually becomes obese. Structured physical exercise can improve or maintain body fitness and reduce obesity[4]. Physical exercises can be grouped into several categories, depending on the purpose of the exercise, so as to affect the physiological changes in the whole system of the body, especially the blood hematological picture. The hematologic system consists of all blood cells, the bone where the mature cells grow and the lymphoid tissue where the blood cells are stored if they are not circulating[5,6]. The hematology system is designed to carry oxygen and nutrients, transport hormones, remove waste products and deliver cells to prevent infection, stop bleeding and facilitate the healing process. Blood also allows the body to feed and heal itself and connect between body parts[7]. Hemoglobin is one component of blood hematology and composed of red blood cell components that can bind oxygen. It underlies that hemoglobin has an important role in sports, especially longterm sports. Long-lasting exercise requires sufficient energy and lasts longer to move muscles. The energy used to move the muscle is produced by burning food with oxygen previously carried by hemoglobin. Therefore, hemoglobin plays an important role in the formation of energy, especially aerobic energy systems[5,6]. The effect of exercise on the body that occurs as a result of exercise is determined by the intensity of the exercise, the intensity of the mild to moderate exercise is highly recommended in obese people, as well as in exercises with too much exercise intensity / weight then the resulting effect is different $[3,4]$. Exercise or physical exercise should be done regularly to make the body more healthy and fit. But in people with obesity or overweight conditions, not all exercise is good to do. Because often this activity actually raises new problems in the joints, especially injury to the knee and ankle because of excess weight [8]. Exercise is appropriate and recommended for the condition of obesity is with exercise in the water sport [7,9]. Movements that can be done in the water include aqua jogging, aqua run, aquarobic or ro ad by the pool. The purpose of this research is to know the effect of moderate intensity aqua jogging exercise on hematology (levels of erythrocytes, hemoglobin level, and hematocrit value) in obese women. Aqua jogging is a form of slow-running exercise done in water[10]. While doing aqua jogging, the feet touch the bottom of the pool, making it safe from injury. The key to aqua jogging is to keep the upper body straight and not too forward, this movement is slightly different from the movement of the road on the ground. Another movement in aqua jogging is knee position should be raised higher and like kicking water, this movement allows the body to stay upright so that aqua jogging movement can be done as running on land[11,12].

\section{MATERIALS AND METHODS}

\section{A. Participants}

36 obese women $\left(\mathrm{BMI}>25 \mathrm{~kg} / \mathrm{m}^{2}\right)$, aged $45-50$ years, who had not attended gymnastics for at least 6 months prior to the study. The participants were divided into 3 groups: (1) aqua jogging 4 times / week for 8 weeks $(n=12)$, and (2) resistance training 4 times / week for 8 weeks $(n=12)$ and control group $(\mathrm{n}=12)$.

\section{B. Research procedure}

Before treatment, the participant is informed about all procedures and benefits related to the research through verbal and written communication, in accordance with the procedure approved by the ethical research team of Dr. Kariadi, Semarang. Participants signed informed consent before being 
given treatment. Initial inspection is done at the first meeting in the morning. Body mass index examination and body composition using Body Composition Monitor (Omron HBF$375)$.

\section{Aqua jogging Procedure}

Increasing heart rate during exercise in the water is more difficult than when exercising on land. Because $65-95 \%$ body cells consist of water, the blood circulation during exercise in the water gets better, meaning that when doing the exercises in the water the heart does not have to pump hard to circulate oxygen. Heart rate monitors are performed every 5 minutes of the exercise period. Aqua jogging given in moderate intense (75\% HRmax) 4 times a week ( 1 hour at a time) for 8 weeks.

1. 10 minutes (combination of static and dynamic exercise)

2. 10-20 minutes, first core exercise, combination of aqua jogging and stretching movements.

3. 25 minutes of second core practice combination of formation exercises by hand in the air (feet continue to perform running motion in the water.

4. 10 minutes of cooling down exercise, using fun games continued cooldown.

\section{Resistance training}

Four times a week ( $1 \mathrm{hr}$. at a time) for 8 weeks. Treatment begins in the first week after the pre-test. Heating using treadmill for 15 minutes, continuing endurance training program 8-13 times repetition with exercise $50-75 \%$ from maximum repetition amount of each participant. Treatment is given 3 sets of repetitions of leg press movement, leg curl, chest press, latissimus pulldown, shoulder press, bicep curl and crunches. progressively and progressively the program for 8 weeks from the entire program.

\section{E. Pre-test and Post-test}

Pre-test measurements first day before treatment. Posttesting performed at the last meeting of the exercise after 8 weeks for three groups. Post-test measurement is identical to pre-test (body mass index, hemoglobin level, hematocrit and erythrocyte).

\section{F. Statistical analysis}

Statistical analysis using one-way ANOVA and statistical analysis using SPSS software version 21 (SPSS Inc., Chicago, IL, USA). Statistical significance is set at $\mathrm{p}<0.05$ and the data is presented as the mean and standard deviation.

\section{RESULTS AND DISCUSSION}

Exercise is a stressor for the body, the body is forced to perform more activities than usual. More activity requires more oxygen supply, especially activity using aerobic energy system. Exercise not only requires more oxygen but can also produce free radicals in the body. During exercise the body will produce reactive oxygen species (ROS), which are free radicals. Even when the body is inactive, a small amount of ROS is still produced. ROS can disrupt the physiological state of the body. This condition makes the body will respond by enhancing the activity of superoxide dismutase (SOD) and protective enzymes in the blood. In addition, high ROS effects can lead to high hemoglobin breakdown. High oxygen consumption and the presence of free radicals in the body can lead to changes in the suitability of hemoglobin during exercise $[13,14]$. Changes due to aqua jogging exercises are presented in figure 1.

\begin{tabular}{|c|c|c|c|c|}
\hline Variable & $\begin{array}{l}\text { Aquajogging Group }(\mathrm{n}=12) \\
(\text { Mean } \pm \text { SD) }\end{array}$ & $\begin{array}{c}\text { Resistance Training } \\
(\mathrm{n}=12) \\
(\text { Mean } \pm \mathrm{SD})\end{array}$ & $\begin{array}{l}\text { Control group }(\mathrm{n}=12) \\
\text { (Mean } \pm \text { SD) }\end{array}$ & $p$ \\
\hline$\overline{\text { Age }}$ & $46.74 \pm 1.30$ & $46.49 \pm 1.30$ & $46.79 \pm 1.35$ & 0.225 \\
\hline Calori (ccal) & $21.25 \pm 165.81$ & $2157 \pm 119.97$ & $2134 \pm 136.11$ & 0.112 \\
\hline BMI $(\mathrm{kg} / \mathrm{m} 2)$ pre-test & $31.29 \pm 0.98$ & $31.72 \pm 1.13$ & $32.47 \pm 1.55$ & 0.319 \\
\hline BMI $(\mathrm{kg} / \mathrm{m} 2)$ post test & $30.29 \pm 1.15$ & $32.86 \pm 0.93$ & $32.46 \pm 1.54$ & $0.000^{7}$ \\
\hline Haemoglobin $(\mathrm{g} / \mathrm{d})$ pre-test & $12.90 \pm 0.76$ & $12.97 \pm 1.11$ & $12.88 \pm 0.82$ & 0.779 \\
\hline Haemoglobin (g/dl)post-test & $15.00 \pm 2.83$ & $13.97 \pm 1.18$ & $12.49 \pm 0.84$ & 0.001 \\
\hline Hematocrit $(\%)$ pre-test & $38.80 \pm 2.77$ & $38.37 \pm 2.44$ & $35.77 \pm 1.31$ & 0.116 \\
\hline Hematocrit (\%) post-test & $43.96 \pm 2.25$ & $41.80 \pm 3.17$ & $34.89 \pm 1.31$ & $0.000^{\prime \prime}$ \\
\hline Eritrocyte $(\mu l)$ post-test & $4.50 \pm 0.40$ & $4.54 \pm 0.19$ & $4.29 \pm 0.15$ & 0.038 \\
\hline Eritrocyte $(\mu l)$ post-test & $4.59 \pm 0.83$ & $5.01 \pm 0.18$ & $4.22 \pm 0.57$ & $0.000^{\prime}$ \\
\hline
\end{tabular}

Fig. 1 General characteristics of the subjects $(n=36)$

Age of the participants, caloric intake, none were statistically different, while Body Mass Index, hemoglobin, hematocrit and erythrocyte levels after exercise were significantly different $(\mathrm{p}<0.05)$. Body mass index in each aqua jogging group, endurance training and control group of ($1.01 \pm 0.70 ;-1.14+0.73 ; 0.01+0.01 ; \mathrm{p}<0.05)$ Increased hemoglobin levels in the aqua jogging group, endurance training and group control $(2.10 \pm 3.03,1.50+0.39,0.30+$ $0.15, \mathrm{p}<0.05)$. Increased hematocrit level in aqua jogging group, endurance training and group control $(5.15 \pm 2.63 ; 3.43$ $+5.15 ; 0.88+0.34 ; \mathrm{p}<0.05)$. Increased levels of erythrocytes in aqua jogging groups, endurance training and group control $(0.09 \pm 0.63 ; 0.46+0.6 ; 0.07+0.54 ; \mathrm{p}<0.05)$. Increased hemoglobin levels a significant in aqua jogging were higher than the resistance training and control group.

\section{A. Body Mass Index}

Changes in BMI in aqua jogging exercises caused by weight loss and changes in body composition, there is a loss of large amounts of water, electrolytes, minerals and proteins located in the fat tissue accompanied by the use of stored liver and muscle glycogen. For each loss of $1 \mathrm{~g}$ of glycogen is always accompanied by a water loss of 2.5 grams. Skeletal muscle contractions (40\%) of all body tissues require energy source substrate [15] energy reserves in skeletal muscle are required to meet energy requirements during contractions. One of the fulfillment of these sources is through the mechanism of lipolysis. Lipolysis occurs by epinephrine exposure through the mechanism of activity of beta adrenergic responses secreted during stress on physical exercise and immediately after physical exercise [16,17]. Increased lipolysis in physical exercise may decrease adipocyte fat content in adipocyte cells, decrease in adipocyte size further leads to a decrease in fatty tissue mass. The energy used for aqua jogging exercises mainly comes from fat, because fat will produce more energy than carbohydrates and proteins [18]. The results of this study supported previous research that physical exercise $25 \%-60 \%$ 
VO2Max increase fat oxidation 5 -10 times. Increased lipolysis occurred after 30 minutes in untrained subjects and in the untrained subjects lipolysis was slower[19,20] Increased body mass index in the resistance training group is associated with weight gain[21]. Resistance training directly affects the muscles by increasing the number of sarcomeres and carbon fibers, i.e. actin filaments and myosin's required for muscle contraction. The addition of new muscle fibers causes increased muscle strength resulting in weight gain. Another study reported that muscle glycogen increased from level of $13-15$ grams / $\mathrm{kg}$ of muscle to 40 grams / $\mathrm{kg}$ muscle or 2.5 times as a result of exercise[22].

\section{B. Hemoglobin}

Hemoglobin is a globular molecule formed from four sub units. Each sub unit contains a hem that joins the polypeptide. Hem is a porphyrin-containing derivative of iron. The overall polypeptide is expressed as a part of the globin of the hemoglobin molecule. There are two pairs of polypeptides in each hemoglobin molecule, two sub-units containing another polypeptide. In hemoglobin in normal adult humans (hemoglobin $\mathrm{A} / \mathrm{Hb} \mathrm{A}$ ) two types of polypeptides are called $\alpha$ chains, each containing 141 amino acid residues and $\beta$ chains each containing 146 amino acid residues. [5,23] The measured hemoglobin levels are in red blood granules. The number of hemoglobin in normal blood is about $15 \mathrm{gr}$ every $100 \mathrm{ml}$ of blood and this amount is usually called $100 \%$ [24] The threshold limit for hemoglobin level is $>13 \mathrm{gr} / \mathrm{dl}$ for adult males and $>12 \mathrm{gr} / \mathrm{dl}$ for women. The range of normal hemoglobin levels for children 12-14 years is between 12-15 $\mathrm{gr} / \mathrm{dl}$. As for men 15 years and over have a range of hemoglobin levels 13-16 gr / dl. The hemoglobin level in the blood of the athlete should be normal. If the hemoglobin level is below the normal limit, then an athlete cannot meet the necessary energy requirements. However, levels of hemoglobin that exceed the upper limit of normal harmful to the athlete. The condition is because during practice there will be saturation of hemoglobin in the blood, on the other hand the partial pressure of blood and heart rate is also increased. This can be harmful to the body because at any time can occur sudden heart failure. Moreover, with conditions of high hemoglobin levels that allow saturation to occur faster and more saturated than low hemoglobin levels. This situation must be anticipated by the athlete. Therefore, hemoglobin levels should remain normal in the blood.

\section{Hematocrit}

Levels of hematocrit in aqua jogging and resistance training groups showed that there was a significant difference between the hematocrit value in the initial test and the hematocrit value after the first eight weeks as well as the experimental group there was a very significant change. $[25,26]$ After 8 weeks of striking exercise, aerobic exercise may be compensated by increased erythrocyte activity in the formation of erythrocytes. Another possibility is that the above exercises have not been able to increase the activity of erythropoietin, but there is a change of hematocrit (from normal to high) so that the amount of erythrocytes increases, as a result of an increase in blood hematocrit[14,27]. This exercise can also be affected by the modulator that regulates the water composition in the body, so that the process of decreasing the water in the blood for each individual is different with the final effect of the blood hematocrit level constantly increasing, even apparent at the beginning of the exercise (pre-test). Furthermore, this exercise is done over a period of time physiologically will be adapted as an activity that gives effect to the increase of erythrocytes. [28]Other possibilities are caused by: poor diet control, behavioral influences and environmental changes that are not well controlled.

\section{Erythrocyte}

There was no significant difference between erythrocyte level in pretest and erythrocytes after the first eight weeks, even up to eight weeks later, whereas based on the results of the test on the variables of erythrocytes in the treatment group, there was no significant difference between erythrocyte preliminary test and erythrocyte level after eight weeks of exercise, also on the final test. The above condition may be due to the doses that are capable of stimulating the erythrocyte-forming components to work optimally, whereas theoretically the opposite is that oxygen levels of the muscles in the exercise may be expected to decrease sharply during exercise and the pressure of carbon dioxide in venous blood increases well above normal [7] so the erythrocyte-O2 bond tends to be weaker than the erythrocyte- $\mathrm{CO} 2$ bond, and as a balancing of the blood-related erythrocytes breakdown during heavy exercise, moderate intensity exercises allow the replacement of erythrocytes to become new and eliminate new blood fragility due to strenuous exercise[29].

\section{CONCLUSION}

The continuous bout of exercise was a good control for the high intensity, repeated Wingate exercise bout since both tests accomplished the same amount of work. This allows the effects of intensity to be compared while factoring out duration of exercise.

\section{ACKNOWLEDGMENT}

This study was granted by the Ministry of Research, Technology and Higher Education of Indonesia and Research Funds Program of the Semarang State University, Indonesia (2017).

\section{REFERENCES}

[1] Hermawan AG, Komplikasi Obesitas dan Usaha Penanggulangannya, Ann Intern Med. 1991;d(68):39-41.

[2] Bessesen DH, Update on Obesity, 2008, 93(June):2027-34.

[3] Vincent HK, Vincent KR, Bourguignon C, Braith RW, "Obesity and postexercise oxidative stress in older women", Med Sci Sports Exerc, 2005, 37(2):213-9.

[4] Jakicic JM, Otto AD, "Physical activity considerations for the treatment and prevention of obesity", Am J Clin Nutr, 2005 Jul;82(1 Suppl):226S229S.

[5] Prandoni P, Lensing AWA, Prins MH, Stamler JS, "Hemoglobin and Nitric Oxide", 2003, 402-5.

[6] Decker H, Nadja H, "Negative cooperativity in Root-effect hemoglobins: role of heterogeneity", Integr Comp Biol, 2007 Oct. 
[7] PUGH CJA, SPRUNG VS, ONO K, SPENCE AL, THIJSSEN DHJ, CARTER HH, et al, "The Effect of Water Immersion during Exercise on Cerebral Blood Flow", Med Sci Sport Exerc, 2015, 47(2):299-306.

[8] Sinha A, Kling S, "A review of adolescent obesity: Prevalence, etiology, and treatment", Vol. 19, Obesity Surgery, 2009, p. 113-20.

[9] Dundar U, Solak O, Toktas H, Demirdal US, Subasi V, Kavuncu V, et al, "Effect of aquatic exercise on ankylosing spondylitis: a randomized controlled trial", Rheumatol Int, 2014,1-7.

[10] Wouters EJM, Van Nunen AMA, Geenen R, Kolotkin RL, Vingerhoets AJJM, "Effects of aquajogging in obese adults: A pilot study" J Obes, 2010.

[11] Welfare S, Sciences R "Effectiveness of Aquatic Exercise Therapy on the Quality of Life in Women with Knee Osteoarthritis", 2016, October 2015.

[12] Delevatti R, Marson E, Kruel LF, "Effect of aquatic exercise training on lipids profile and glycaemia: A systematic review. Rev Andaluza Med del Deport" Consejería de Educación, Cultura y Deporte de la Junta de Andalucía, 2015, 8(4):163-70.

[13] Kundu S, Premer S a, Hoy J a, Trent JT, Hargrove MS, "Direct measurement of equilibrium constants for high-affinity hemoglobins", Biophys J2003 Jun, 84(6):3931-40.

[14] Wirnitzer KC, Faulhaber M, "Hemoglobin and hematocrit during an 8 day mountainbike race: A field study", J Sport Sci Med, 2007, 6(2):2656.

[15] Kumar V, Atherton P, Smith K, Rennie MJ, "Human muscle protein synthesis and breakdown during and after exercise", J Appl Physiol, 2009, Jun 106(6):2026-39.

[16] Phillips SM, Green HJ, Tarnopolsky M a, Heigenhauser GF, Hill RE, Grant SM, "Effects of training duration on substrate turnover and oxidation during exercise", J Appl Physiol, 1996 Nov, 81(5):2182-91.

[17] van Aggel-Leijssen DP, Saris WH, Hul GB, van Baak M, "a. Short-term effects of weight loss with or without low-intensity exercise training on fat metabolism in obese men”, Am J Clin Nutr 2001 Mar; 73(3):52331.

[18] Punyadeera C, Zorenc AHG, Koopman R, McAinch AJ, Smit E, Manders R, et al., "The effects of exercise and adipose tissue lipolysis on plasma adiponectin concentration and adiponectin receptor expression in human skeletal muscle", Eur J Endocrinol, 2005 Mar;152(3):427-36.

[19] Laye MJ, Rector RS, Borengasser SJ, Naples SP, Grace M, Ibdah JA, et al., "Cessation of daily wheel running differentially alters fat oxidation capacity in liver, muscle, and adipose tissue", 2010, 161-8.

[20] Manning K, Effects of Exercise Training on Fat Oxidation in Untrained Overweight and Obese Females, 2011.

[21] Reid IR, Relationships between fat and bone. Osteoporos Int, 2008 May, 19(5):595-606.

[22] Rose AJ, Richter E a, "Regulatory mechanisms of skeletal muscle protein turnover during exercise", J Appl Physiol, 2009 May [cited 2013 Sep 21], 106(5):1702-11.

[23] Features G, Hemoglobin OF, Patients D. The New England Journal of Medicine GENETIC AND CLINICAL FEATURES OF HEMOGLOBIN H DISEASE IN CHINESE PATIENTS. 2000.

[24] Stamler JS, Jia L, Eu JP, McMahon TJ, Demchenko IT, Bonaventura J, et al., "Blood flow regulation by S-nitrosohemoglobin in the physiological oxygen gradient. Science", 1997 Jun 27, 276(5321), 2034-7.

[25] Boning D, Maassen N, Pries a. R, "The optimal hematocrit increases during exercise", J Appl Physiol, 2012, 113(7):1168-1168.

[26] Ma JZ, Ebben J, Xia H, Collins a J, "Hematocrit level and associated mortality in hemodialysis patients", J Am Soc Nephrol, 1999, 10(3):610-9.

[27] Schuler B, Arras M, Keller S, Rettich A, Lundby C, Vogel J, et al., "Optimal hematocrit for maximal exercise performance in acute and chronic erythropoietin-treated mice', Proc Natl Acad Sci U S A., 2010,107(1):419-23.

[28] Fox EL, Bowers RW FM, "The Physiological Basis of Physical Education and Athletics", USA, W.B Saunders Company, 1988.

[29] Moore A, Timmerman S, Brownlee K, Rubin D, Hackney A. Strenuous, Fatiguing Exercise: Relationship of Cortisol to Circulating Thyroid Hormones", Int J Endocrinol Metab. 2005, 1:18-24. 